\title{
LANDSLIDE INVESTIGATION USING DIFFERENTIAL SYNTHETIC APERTURE RADAR INTERFEROMETRY: A CASE STUDY OF BALLORAN DAM AREA IN SYRIA
}

\author{
M. Hammad ${ }^{1, *}$, L. Mucsi $^{1}$, B. V. Leeuwen ${ }^{1}$ \\ ${ }^{1}$ Department of Physical Geography and Geoinformatics, Faculty of Science and Informatics, University of Szeged, Hungary - \\ (muhannad, mucsi, leeuwen)@geo.u-szeged.hu
}

KEY WORDS: Landslide, Differential, InSAR, Syria, Balloran

\begin{abstract}
:
Landslides are one of the main geological hazards that can cause critical damage to the infrastructure in an area and can result in serious risks to the people's safety there. Landslides can be investigated and monitored using field survey, aerial mapping and high resolution optical satellite data analysis. However, these methods are relatively time-consuming. Interferometric synthetic aperture radar (InSAR) can investigate and monitor landslides and provide sub-centimetre accuracy for ground-surface deformation when time series analysis techniques are employed. In this research, differential synthetic aperture radar interferometry was applied on Sentinel-1 data of two Single Look Complex (SLC) images from 16 October 2018 and 21 March 2019 in the Interferometric Wide (IW) swath mode using the Sentinel application platform (SNAP) to determine the extreme ground-surface deformations, as a prelude to landslides occurrence in Balloran dam area in the north-west of Syria, where the ophiolite complex deposits of the Maastrichtian are exposed causing, due to the heavy rains, several landslides affecting the road network in this area every year. The results reveal ground-surface deformations during the study period along the satellite line of sight near to the main road in Balloran dam area with a maximum value reaches to around $20 \mathrm{~cm}$. The D-InSAR results were compared to the D-GPS results of 10 validation points along the main road in the study area, where the RMS difference value was $20 \mathrm{~cm}$.
\end{abstract}

\section{INTRODUCTION}

It is very necessary to study and monitor all potential geological hazards that may negatively affect the work efficiency of important facilities (Dams, roads... etc.) and thus the safety of people in the same area. Landslides are one of the most important geological hazards which should be always investigated by monitoring the deformation of the ground surface as a direct indicator of a landslide occurrence (Mirzaee et al., 2017; Liu et al., 2018).

Landslides, mudslides, debris flows are all geological hazards involving earth, mud or rocks moving quickly downhills, and it can happen almost anywhere there are slopes. As they occur suddenly and seemingly without warning, they're often deadly. Though estimates vary, these events kill a lot of people every year and cause catastrophic damage to infrastructure in any place where it occurs.

Using advanced remote sensing techniques such as the DInSAR technique to monitor ground-surface deformation has become very common worldwide nowadays because they save time and efforts (Hooper et al., 2012; Rucci et al., 2012; Malenovsky et al., 2012). The basic principle of D-InSAR technique depends on using the phase information of the radar waves to obtain the phase of the ground-surface deformation the so-called displacement phase - from the complex interferogram generated from two images in the repeat-pass mode. The complex interferogram generated by these two images has fringes which represent the different components of the interferogram phase information $\phi_{\text {int }}$ as follows (Mora et al., 2003):

$$
\Phi_{\text {int }}=\phi_{\text {elev }}+\phi_{\text {disp }}+\phi_{\text {atmos }}+\phi_{\text {flat }}+\phi_{\text {noise }}
$$

where $\phi_{\text {elev }}$ is the topographic phase;

$\phi_{\text {disp }}$ is the displacement phase which is caused by the deformation of a ground-surface pixel location along the satellite line-of-sight direction (slant-range);

$\phi_{\text {atmos }}$ is the atmospheric phase which is a signal delay error caused by the changing atmospheric heterogeneities in time and space;

$\phi_{\text {flat }}$ is the flat-earth phase which is an error caused by the curvature of the reference surface;

$\phi_{\text {noise }}$ is the phase of noise caused by either variability in scattering from a pixel, thermal noise or coregistration errors.

Through the interferometric processing, we always try to eliminate other sources of error to be left with only the contributor of interest which is typically either elevation phase or displacement phase which their values are wrapped between $-\pi$ and $+\pi$. The unwrapping process is done by using Snaphu which is a freely available software runs on most Unix/Linux platforms and uses suitable algorithm for phase unwrapping. Interferometric fringes, which represent a full $2 \pi$ cycle, appear on an interferogram as cycles of arbitrary colors. Each cycle representing half the sensor's wavelength. Relative ground movement between two points can be calculated by counting the fringes and multiplying them by half of the wavelength. The closer the fringes are together, the greater the strain on the ground. The good candidate images for producing good interferometric results must have strong similarities and therefore the coherence between master and slave images must be taken in consideration. Loss of coherence can be caused by any of temporal reason due to the different time of acquisitions, geometric reason due to orbit errors or volumetric reason due to the vegetation.

\footnotetext{
* Corresponding author
} 
In general, the relative values of the deformation in LOS direction have a strong relationship with the absolute vertical displacement values, since the line-of-sight deformation is considered as the projection of the vertical displacement on the LOS direction. The linear relation between the subsidence profile and the horizontal displacement measurements in LOS direction can be drawn taking into consideration that the tilt was defined as the first derivative of the subsidence profile (Fig. 1).

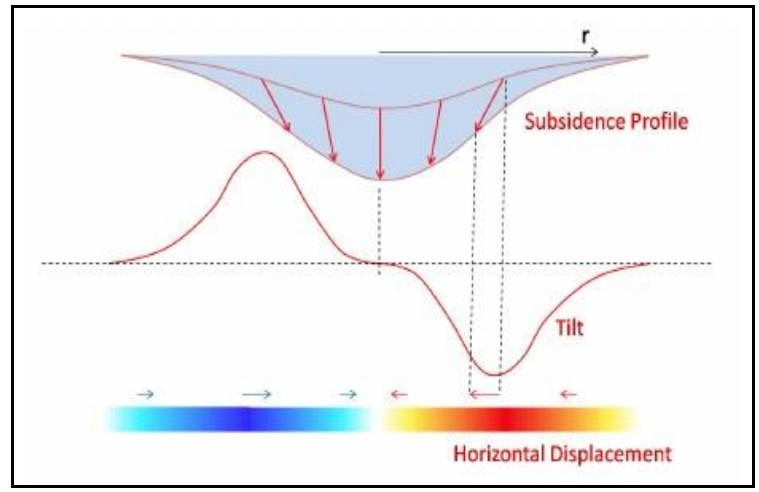

Figure 1. The linear relation between subsidence profile, tilt and horizontal displacement measurements in LOS direction (Samieie-Esfahany et al., 2009).

\subsection{Objectives of the research}

Although, InSAR techniques proved in many countries around the world to be a cost effective remote method of measuring ground surface deformations such as subsidence and landslides, it is good to make a comparison between different methods of landslide monitoring and analysis. Therefore, in this research, we have utilized two different geodetic techniques including the D-InSAR technique and the D-GPS field measurements to analyse ground-surface deformations, as a prelude to landslides occurrence, along the main road in Balloran dam area in the north-west part of Syria, where the ophiolite complex deposits of the Maastrichtian are exposed causing, due to the heavy rainfalls in this area which has an annual average of about 900 $\mathrm{mm}$, several landslides affecting the tourist roads in this area every year and costing the authorities a lot of money for carrying out the maintenance processes of the road network every year. So, using the InSAR techniques and taking the advantages of the free available SAR data and the related software to investigate and monitor landslides and Predict them before they happen, can save a lot of time and efforts of handling the damages which cause by the landslides.

\subsection{Study area}

Baloran dam area is part of Wadi Qandil basin and located in the northern part of Latakia province. This area is characterized by existing of radiolarites and ophiolite complex rocks which belong to the volcanic and sedimentary series (Parrot, 1980). These structurally complex geological formations situated in this area give rise to shallow landslides phenomena, which can be well studied with InSAR-based monitoring techniques.

Balloran dam area is also characterized by the spread of steep inclines with different slope strength, and the presence of these slopes is because of the spread of the mountains of the area, which ranges between around100 and almost 400 meters above the sea level (Fig. 2).
The study area has domestic and tourist roads in addition to one main road which connects Latakia city, the centre of the province, with the tourist towns in the area and the Turkish border. Several villages are located along this main road and most of them suffering every year from landslides which happen frequently there.

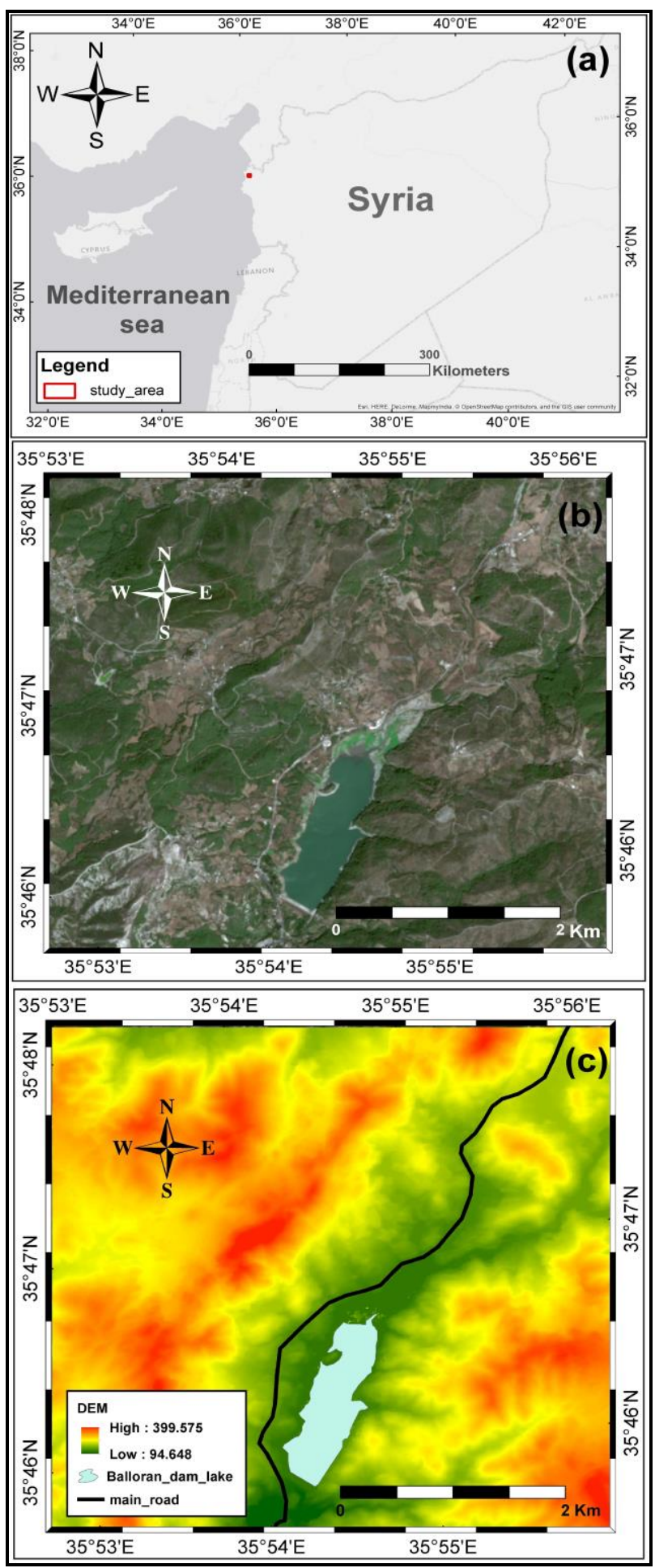

Figure 2. The study area location (a) The location of Balloran dam area in Syria, (b) Google Earth image of Balloran dam area, (c) DEM of the study area and the main road. 


\section{MATERIAL AND METHODS}

Many softwares (SNAP, StaMPS, Doris etc.) have been written for processing SAR data and every kind of software has different algorithmic combinations (Hooper et al., 2013). Sentinel-1 toolbox in SNAP software, which can be used to process different radar data, is a free open-source software and all Sentinel-1 data are free online through Copernicus open access hub.

In this research, D-InSAR technique was employed to detect the ground-surface deformation in Baloran dam area in order to predict the sites, along the main road there, which have the maximum values of ground-surface deformation and thus identify the sites with the greatest probability of landslides occur.

For the D-InSAR technique, Sentinel-1 data of single look complex (SLC) images in interferometry wide swath mode (IW) with VV polarization and descending direction for two acquisition dates 16 October 2018 and 21 March 2019 were coregistered as master and slave, respectively, using Sentinel-1 toolbox in SNAP software (Table 1).

\begin{tabular}{|c|c|c|c|c|}
\hline File Name & Mst/Slv & $\begin{array}{c}\text { Bperp } \\
{[\mathrm{m}]}\end{array}$ & $\begin{array}{c}\text { Btemp } \\
\text { [days] }\end{array}$ & $\begin{array}{c}\text { Modeled } \\
\text { Coherence }\end{array}$ \\
\hline $\begin{array}{c}\text { S1B_IW_SLC_ } \\
\text { 1SD_20181016 } \\
\text { T033410 }\end{array}$ & Master & 0 & 0 & 1.00 \\
\hline $\begin{array}{c}\text { S1B_IW_SLC_ } \\
\text { 1SD_20190321 } \\
\text { T033406 }\end{array}$ & Slave & -28.81 & -156 & 0.84 \\
\hline
\end{tabular}

Table 1. Overview of Sentinel-1 data used in D-InSAR technique in this research

These two images, which have a $-28.81 \mathrm{~m}$ perpendicular baseline and a -156 days temporary baseline, were used after the preparation processes, in our case the split of IW3 sub-swath was done to get the burst related to our study area and the orbit metadata of the product was updated by applying the applyorbit-file tool to provide accurate satellite position and velocity information and after that the SRTM 1-second DEM was used with a bilinear interpolation method in the co-registration process in the back-geocoding tool before applying the Enhanced Spectral Diversity (ESD) method to perform the range and azimuth corrections for every burst, to generate the interferogram of the study area after the subtraction processes for the flat-earth phase and the topographic phase (Fig. 3).

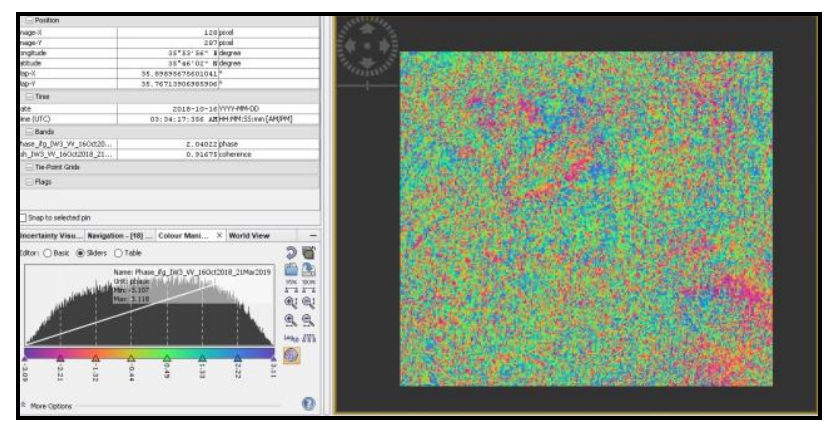

Figure 3. The interferogram of the study area using SNAP for two Sentinel_1B images from (16 October 2018) and (21 March 2019)
The quality of an interferogram depends on the amount of noise that, in general, comes from diverse sources. And the coherence estimation available in SNAP is a good way to have an idea about that.

The coherence estimation for the interferogram of the study area shows values reach to around $95 \%$ which is acceptable taking in consideration that the Balloran dam lake covers a wide area in our case (Fig. 4).

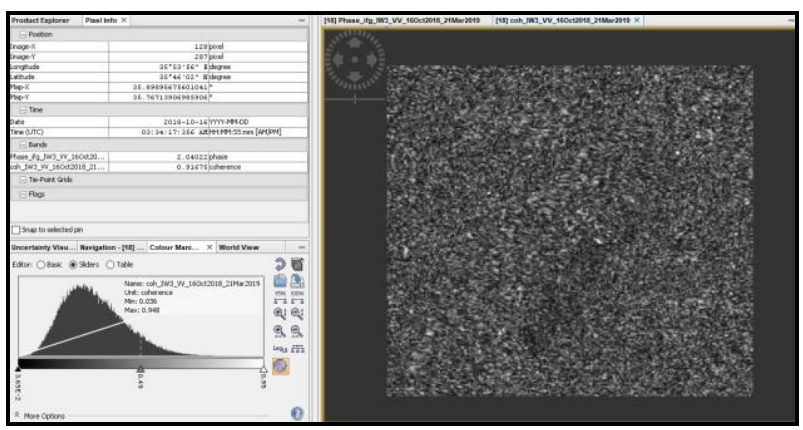

Figure 4. The coherence estimation for the interferogram of the study area

After interferogram formation process, deburst process was applied to seamlessly join all burst data in a sub-swath into one single image to ensure the continuous coverage of the ground (Grandin, 2015).

Since the original SAR image contains inherent speckle noise, Multilook process was applied to reduce the speckle appearance and to improve the image interpretability.

Also, Goldstein phase filtering was applied to the interferogram phase to remove the noise phase from the complex interferogram, which is directly related to interferometric coherence and the look number of the interferogram ( $\mathrm{Li}$ et al., 2008).

Then, with the help of SNAPHU which is a statistical-cost network-flow algorithm for phase unwrapping developed at Stanford University and available for Linux operating systems only, the interferogram phase was unwrapped to recover the integer number of cycles so it can be added to the wrapped phase of the complex interferogram in order to get the unwrapped phase (Ferretti et al., 2007).

Finally, the values of the unwrapped phase were converted into displacement values using SNAP in order to get the relative ground-surface deformation values in the LOS direction.

Since, the results are still in radar geometry, moreover due to topographical variations of a scene and the tilt of the satellite sensor, the distances can be distorted in the SAR images. Therefore, terrain correction was applied to compensate for the distortions and re-project the scene to geographic projection using Range Doppler Terrain Correction tool and the geographic latitude/longitude (WGS 84) as a coordinate reference system for the map projection.

All the previous steps of producing ground-surface deformation values' map using D-inSAR technique are shown in order in the following chart (Fig. 5). 


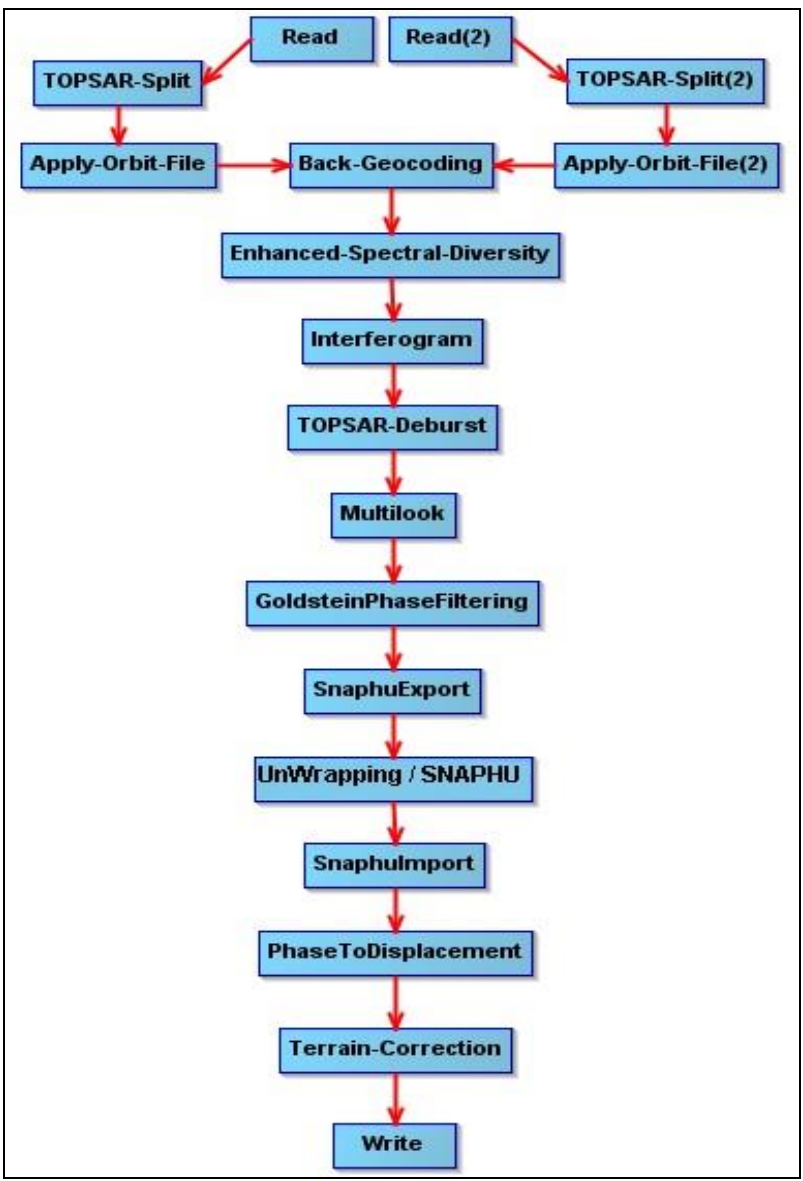

Figure 5. The flow chart of producing ground-surface deformation values' map using D-inSAR technique.

For the D-GPS field measurements, two campaigns have been carried out before and after the study period using (Leica GPS system 550) set to get the data for 10 reference or validation points along the main road in Balloran dam area to detect the ground- surface deformation. Differential GPS base station established by the General Organization of Remote Sensing (GORS) in Latakia city, Syria was used as starting / closing reference point in our field measurements. At each validation point, the geographic coordinates were measured through timebased averaging, minimum of 30 minutes' observation time, until the accuracy indicated in the receiver becomes acceptable. Later, a shape file was generated from the difference of the measurement values for each gathered point from the two campaigns.

At the end, all the results from the D-InSAR technique and the D-GPS field measurements were re-projected to the UTM 35 North coordinate reference system using ArcGIS to be able to compare both of two results.

\section{RESULTS AND DISCUSSION}

In this research, both of the D-InSAR technique and the D-GPS field measurements were able to detect ground-surface deformation in the study area.

D-InSAR time-series analyses in this research indicates the presence of line-of-sight (LOS) ground-surface deformation in Baloran dam area during the study period (Fig. 6).

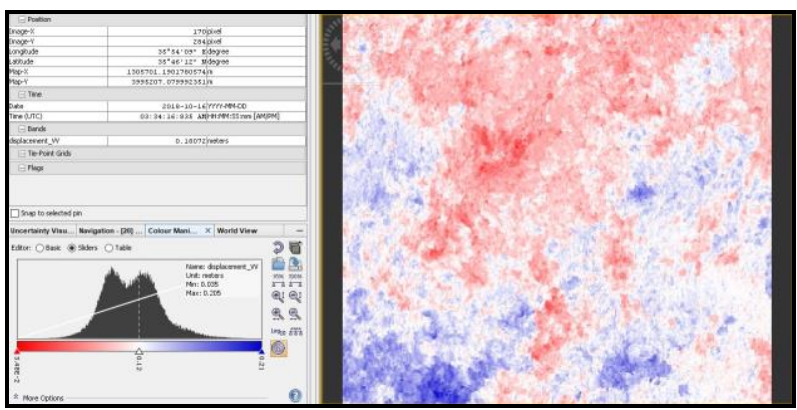

Figure 6. Displacement values in Baloran dam area using DInSAR technique for two Sentinel_1B images from (16 October 2018) and (21 March 2019)

Mainly, in InSAR, the results of ground-surface deformation with positive values correspond to the motion toward the satellite, and the results of ground-surface deformation with negative values correspond to the motion reverse the satellite.

The D-InSAR technique in this research shows ground-surface deformation along the main road in the study. The maximum ground-surface deformation values between 16 October 2018 and 21 March 2019 along the main road in the study area were in two sites and reached to around $+20 \mathrm{~cm}$ in the satellite lineof-sight direction, the first site was near to Al-Qara'niya village beside the dam location in the South part of the study area and the other site was near to Al-Hayek village North-East of the lake. The ground-surface deformation values from the D-InSAR technique were reclassified in ArcGIS using Natural Break method into five classes and the highest two classes were overlaid on an optical image from the Google Earth with the help of ArcGIS to make the results more clearly along the main road in the study area. The ground-surface deformation values of the other parts of the main road in the study area were less than $10 \mathrm{~cm}$ (Fig. 7).

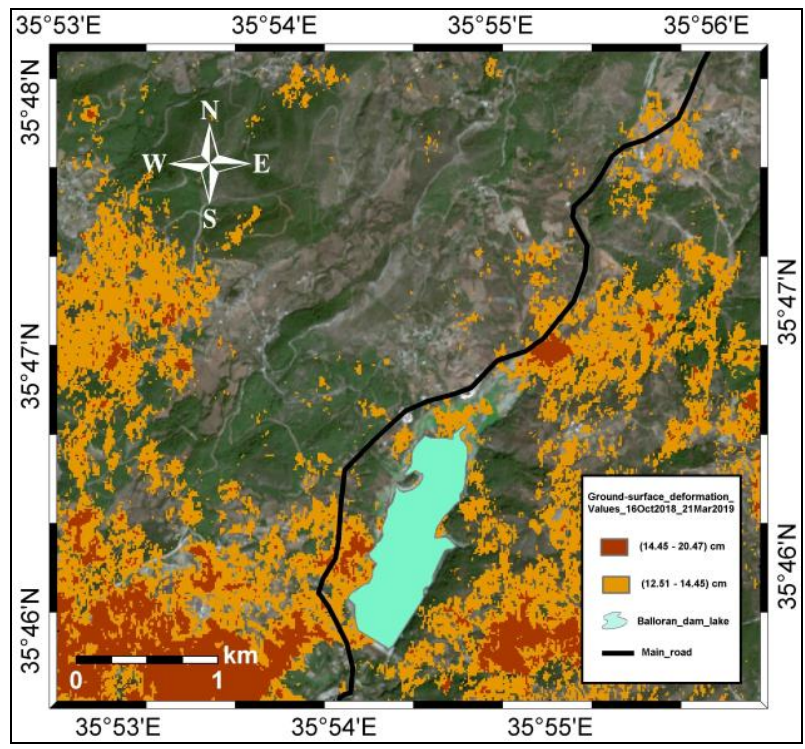

Figure 7. Ground-surface deformation values in Baloran dam area using D-InSAR technique for two Sentinel_1B images from (16 October 2018) and (21 March 2019) overlaid on an optical image from the Google Earth as a base map 
On the other hand, the results of D-GPS field measurements from the two campaigns in this research show ground-surface deformation in the 10 reference points during the study period. The maximum ground-surface deformation value in the study area was at the reference point P3 with a value reaches to $75 \mathrm{~cm}$ in the South-East direction. However, the ground-surface deformation values of the other reference points were between 2 and $5 \mathrm{~cm}$ during the study period (Fig. 8).

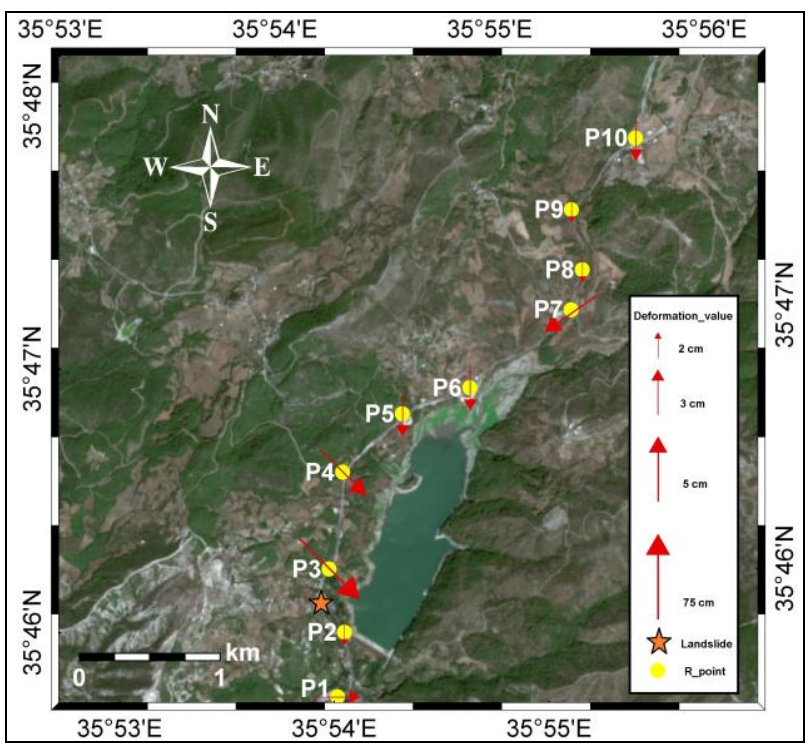

Figure 8. Ground-surface deformation magnitude and direction values using D-GPS measurements of 10 reference points along the main road in the study area and the star indicate to the latest landslide location

During the study period, a landslide was occurred in the study area in the beginning of March 2019 near to the dam location, as shown in the last figure, the maximum magnitude of this landslide reaches to around $1 \mathrm{~m}$ to the South - South East direction (Fig. 9).

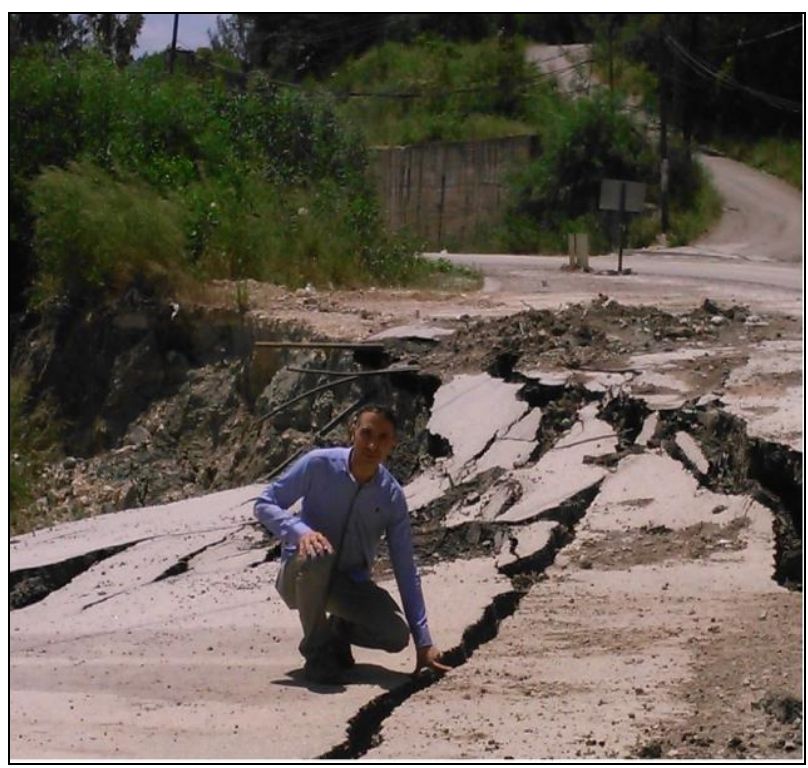

Figure 9. Ground picture of the latest landslide in the study area near to the dam location (March, 2019)
The comparison between the results of the D-InSAR technique at the 10 sites of the validation points gathered by the D-GPS and the results of the D-GPS field measurements has showed a difference at all the 10 validation points. The maximum difference was at the validation point P3 near the landslide location and reached to around $59 \mathrm{~cm}$ due to the effect of the landslide near to this point which has almost North - East direction and this direction is parallel to the Sentinel-1B satellite azimuth direction which makes the detecting process of the ground-surface deformation in this site using Sentinel-1 SAR data difficult to achieve by use D-InSAR technique, and maybe it needs another interferometric technique to do that. The minimum difference value was at the validation point P8 and reached to around $6 \mathrm{~cm}$. At the end, The RMS difference value between the two results was calculated and reached to around $20 \mathrm{~cm}$ (Table 2).

\begin{tabular}{|c|c|c|c|}
\hline $\begin{array}{c}\text { Validation } \\
\text { point name }\end{array}$ & $\begin{array}{c}\text { D-InSAR } \\
\text { results }\end{array}$ & $\begin{array}{c}\text { D-GPS } \\
\text { results }\end{array}$ & $\begin{array}{c}\text { Difference } \\
\text { values }\end{array}$ \\
\hline p1 & 10.64 & 3.10 & 7.54 \\
\hline P2 & 12.97 & 2.04 & 10.93 \\
\hline P3 & 16.20 & 75.07 & 58.87 \\
\hline P4 & 12.83 & 5.06 & 7.77 \\
\hline P5 & 10.77 & 3.12 & 7.65 \\
\hline P6 & 10.56 & 3.02 & 7.54 \\
\hline P7 & 12.10 & 5.08 & 7.02 \\
\hline P8 & 8.810 & 2.41 & 6.4 \\
\hline P9 & 10.11 & 2.03 & 8.08 \\
\hline P10 & 12.35 & 3.05 & 9.3 \\
\hline \multicolumn{2}{|c|}{ RMS $=\sqrt{405.976=20.1488 ~ c m ~}$} \\
\hline
\end{tabular}

Table 2. The difference between the results of both D-InSAR and D-GPS at the ten validation points along the main road in the study area and the root mean square of these differences

\section{CONCLUSION}

This research demonstrates the potential and capability of Radar satellite data and In-SAR time-series technique to investigate and monitor the ground-surface deformation, and also to measure centimetre variations in the line-of-sight distance over time using freely available data and software.

The D-InSAR technique can be considered as an attractive technique and operational tool for geological hazards tasks such as landslides and ground-surface deformation detecting and monitoring.

These kind of studies is very important to monitor the safety of the road network especially in areas with high precipitation and frequent landslides.

Above all, satellite-data-based ground-surface deformation precise calculations are complementary to the field measurements and guide them, but for sure do not replace them.

\section{REFERENCES}

Ferretti, A., Monti-Guarnieri, A., Prati, C., Rocca, F., Massonnet, D., 2007. InSAR principles: guidelines for SAR interferometry processing and interpretation. ESA Publications, TM-19. ISBN 92-9092-233-8. 
Grandin, R., 2015. Interferometric processing of SLC Sentinel1 TOPS data. Proceedings of the 2015 ESA Fringe workshop, ESA Special Publication, SP-731, Frascati, Italy.

Hooper, A., Bekaert, D., Spaans, K., Arıkan, M., 2012. Recent advances in SAR interferometry time series analysis for measuring crustal deformation. Tectonophysics, 514-517:1-13. doi.org/10.1016/j.tecto.2011.10.013.

Hooper, A., Bekaert, D., Spaans, K., 2013. Stamps/MTI Manual Version 3.3 b1. University of Leeds: Leeds, UK.

Liu, X., Zhao, C., Zhang, Q., Peng, J., Zhu, W., Lu, Z., 2018. Multi-Temporal Loess Landslide Inventory Mapping with C-, X-and L-Band SAR Datasets-A Case Study of Heifangtai Loess Landslides, China. Remote Sensing, 10(11), p.1756.

Li, Z.W., Ding, X.L., Huang, C., Zhu, J.J., Chen, Y.L., 2008. Improved filtering parameter determination for the Goldstein radar interferogram filter. ISPRS Journal of Photogrammetry and Remote Sensing, 63(6), pp.621-634.

Malenovsky, Z., Rott, H., Cihlar, J., Schaepman, M.E., GarciaSantos, G., Fernandes, R., Berger, M., 2012. Sentinels for science: Potential of Sentinel-1, -2, and -3 missions for scientific observations of ocean, cryosphere and land. Remote Sensing of Environment, 120: 91-101. doi.org/10.1016/j.rse.2011.09.026.

Mirzaee, S., Motagh, M., Akbari, B., 2017. Landslide monitoring using insar time-series and GPS observations, case study: Shabkola landslide in northern Iran. International Archives of the Photogrammetry, Remote Sensing and Spatial Information Sciences-ISPRS Archives 42 (2017), Nr. 1W1, 42(1W1), pp.487-492.

Mora, O., Mallorqui, J.J., Broquetas, A., 2003. Linear and nonlinear terrain deformation maps from a reduced set of interferometric SAR images. IEEE Transactions on Geoscience and Remote Sensing, 41(10), pp.2243-2253.

Parrot, J.F., 1980. The Baër-Bassit (Northwestern Syria) ophiolitic area. Ofioliti, 2, pp.279-295.

Rucci, A., Ferretti, A., Guarnieri, A.M., Rocca, F., 2012. Sentinel 1 SAR interferometry applications: The outlook for sub millimeter measurements. Remote Sensing of Environment, 120, pp.156-163.

Samieie-Esfahany, S., Hanssen, R., van Thienen-Visser, K., Muntendam-Bos, A., 2009. On the effect of horizontal deformation on InSAR subsidence estimates. In Proceedings of the Fringe 2009 Workshop, Frascati, Italy (Vol. 30). 